\title{
Interstitial high-dose-rate brachytherapy using cobalt-60 source for cervical cancer: dosimetric and clinical outcomes from a single institute
}

\author{
Mohan Kumar, MD, Revathy Thangaraj, MSc, Ram Charith Alva, MD, Kirthi Koushik, MD, Arul Ponni, MD, \\ Manur Gururajachar Janaki, MD \\ Ramaiah Medical College, Bengaluru, India
}

\begin{abstract}
Purpose: To record and report dosimetric and clinical outcomes of interstitial brachytherapy using cobalt-60 $\left({ }^{60} \mathrm{Co}\right)$ source in cervical cancer.

Material and methods: Seventy patients who underwent external beam radiotherapy with dose of 45 Gy in 25 fractions, followed by interstitial brachytherapy (ISBT) 6.5 Gy $\times 4$ fractions were included into this study. The ISBT applicators were inserted under combined spinal and epidural anesthesia. Computed tomography (CT) simulation was performed and axial CT images were transferred to treatment planning system. High-risk clinical target volume $\left(\mathrm{CTV}_{\mathrm{HR}}\right)$ and organs at risks (OARs) were contoured. Four fractions of $6.5 \mathrm{~Gy}$ were prescribed to $\mathrm{CTV}_{\mathrm{HR}}$ using inverse planning technique. Patients were followed-up for 3 years. Dosimetric parameters and clinical outcomes were recorded and compared with available literature.

Results: Seventy patients with FIGO stage IIB-IVA were included in the study. The median $\mathrm{EQD}_{2}$ of $2 \mathrm{~cm}^{3}$ of bladder, rectum, sigmoid and $\mathrm{D}_{90} \mathrm{CTV}_{\mathrm{HR}}$ were $70 \mathrm{~Gy}$ (53-75 Gy), 64 Gy (51-71 Gy), 48 Gy (44-72 Gy), and 77 Gy (70-86 Gy), and dose homogeneity index (DHI), dose non-uniformity ratio (DNR), coverage index (CI), overdose volume index (OI), and conformal index (COIN) were 0.58 (0.39-0.78), $0.42(0.22-0.61), 0.87(0.59-0.97), 0.19(0.09-0.30)$ and $0.74(0.52-$ $0.85)$, respectively. Local control rate at 2 years was $87.14 \%$. Eight patients had local recurrence and one patient had lung metastasis. Also, two patients with local recurrence had recto-vaginal fistula. Two patients had grade 2 proctitis $(2.8 \%)$ and one patient developed grade 3 proctitis $(1.4 \%)$. There was no grade 2 or higher bladder toxicity.

Conclusions: The dosimetric parameters, local control and toxicities of high-dose-rate interstitial brachytherapy in cervical cancer patients treated by ${ }^{60} \mathrm{Co}$ radioactive source are similar, compared to available literature using iridium-192 ( $\left.{ }^{192} \mathrm{Ir}\right)$ source.

J Contemp Brachytherapy 2020; 12, 4: 351-355 DOI: https://doi.org/10.5114/jcb.2020.98114
\end{abstract}

Key words: interstitial brachytherapy, cobalt-60, cervical cancer.

\section{Purpose}

Concurrent chemo-radiation is the standard of care for locally advanced cervical cancer patients [1]. Radiotherapy is delivered in the form of external beam radiotherapy (EBRT) and brachytherapy (BT). BT plays a major role in delivering higher conformal dose to the tumor and sparing normal tissues. Intracavitary brachytherapy (ICBT) may not deliver adequate dose to the lateral part of parametrium and the lower part of vagina in locally advanced cervical cancer. Interstitial brachytherapy (ISBT) is a benefit to deliver higher dose to the parametrium and vagina $[2,3,4,5]$.

The radioactive sources used for brachytherapy evolved from the era of radium, cesium to iridium and cobalt. Table 1 presents the different brachytherapy sources used [6]. In earlier days, ISBT was delivered by lowdose-rate (LDR) manual loading technique. Currently, it is replaced by high-dose-rate (HDR) remote afterloading technique, because of shorter treatment time and better radiation safety $[5,7,8,9]$. Iridium-192 $\left({ }^{192} \mathrm{Ir}\right)$ is exclusively used in interstitial brachytherapy by most of the institutes because of high specific activity and availability in smaller size. Now, even cobalt- $60\left({ }^{60} \mathrm{Co}\right)$ source is available in miniature form, with a logistical advantage of longer half-life and financially favorable for developing countries [10]. In the literature, there are many dosimetric studies available comparing ${ }^{192} \mathrm{Ir}$ and ${ }^{60} \mathrm{Co}$ brachytherapy sources [11,12]. The present study was performed to record and report the dosimetric and clinical outcomes of HDR interstitial
Address for correspondence: Revathy Thangaraj, MSc, Department of Radiotherapy,

Ramaiah Medical College, Bengaluru, India 560054, phone +91 803608888, ext. 2759, fax: +91 23601924 ,

๑ e-mail: revamscmedphy@gmail.com
Received: 04.09 .2019

Accepted: 18.05 .2020

Published: 21.08.2020 
Table 1. Brachytherapy sources

\begin{tabular}{lccccccc} 
No. & $\begin{array}{c}\text { Radionuclides } \\
{[6]}\end{array}$ & $\begin{array}{c}\text { Atomic number } \\
(\mathrm{Z})\end{array}$ & $\begin{array}{c}\text { Mass number } \\
(\mathrm{A})\end{array}$ & $\begin{array}{c}\text { Half-life } \\
\left(\mathrm{T}_{1 / 2}\right)\end{array}$ & $\begin{array}{c}\text { Mean energy } \\
(\mathrm{MeV})\end{array}$ & $\begin{array}{c}\text { Air kerma rate } \\
\text { constant } \\
\left(\mu \mathrm{Gy} \cdot \mathrm{m}^{2} /\right. \\
\mathrm{GBq} \cdot \mathrm{h})\end{array}$ & $\begin{array}{c}\text { Dose rate } \\
\text { constant } \\
\left(\mathrm{cGy} \cdot \mathrm{h}^{-1}\right) / \\
\left(\mathrm{cGy} \cdot \mathrm{cm}^{2} \cdot \mathrm{h}^{-1}\right)\end{array}$ \\
\hline 1 & Radium & 82 & 226 & 1,600 years & 0.83 & 195 & - \\
\hline 2 & Cesium & 55 & 137 & 30.07 years & 0.66 & 77.3 & 1.11 \\
\hline 3 & Iridium & 77 & 192 & 73.81 days & 0.37 & 108 & 1.12 \\
\hline 4 & Cobalt & 27 & 60 & 5.26 years & 1.25 & 309 & 1.11 \\
\hline $\mathbf{5}$ & Gold & $\mathbf{7 9}$ & $\mathbf{1 9 8}$ & $\mathbf{2 . 7}$ days & $\mathbf{0 . 4 1}$ & $\mathbf{5 6 . 2}$ & $\mathbf{1 . 1 3}$ \\
\hline $\mathbf{6}$ & lodine & $\mathbf{5 3}$ & $\mathbf{1 2 5}$ & $\mathbf{6 0}$ days & $\mathbf{0 . 0 2 8}$ & - & - \\
\hline $\mathbf{7}$ & Palladium & $\mathbf{4 6}$ & $\mathbf{1 0 3}$ & $\mathbf{1 7}$ days & $\mathbf{0 . 0 2 1}$ & - & -
\end{tabular}

brachytherapy using ${ }^{60} \mathrm{Co}$ source in patients with cervical cancer and compare with studies, in which ${ }^{192}$ Ir was used.

\section{Material and methods}

Retrospectively, we analyzed seventy patients of locally advanced cervical cancer, treated from January 2015 to December 2016 with radical intent. Patients from stage IIB to IVA who underwent interstitial implants were included in the study after obtaining the approval of the internal ethical committee of the institution. EBRT was delivered by four field three-dimensional conformal radiotherapy (3D-CRT) technique on Elekta Synergy linac, with $6 \mathrm{MV}$ photon beams, with a dose of $45 \mathrm{~Gy}$ in 25 fractions without midline shielding or parametrial boost. Additionally, concurrent weekly cisplatin chemotherapy $\left(40 \mathrm{mg} / \mathrm{m}^{2}\right)$, followed by four fractions of ISBT of 6.5 Gy per fraction were applied.

\section{ISBT procedure}

Two weeks after the completion of the EBRT, patients received the insertion of ISBT applicator (Syed Neblett template with obturator \pm uterine tandem, and 14 to 20 stainless steel hollow needles) under combined spinal and epidural anesthesia. Rectal enema was given two hours before the procedure to ensure rectal emptiness. Computed tomography (CT) simulation scan without intravenous contrast was performed, with $50 \mathrm{ml}$ of diluted urograffine dye in the bladder and $20 \mathrm{ml}$ in the rectum (Asteion VP; Toshiba). Axial CT slices of $3 \mathrm{~mm}$ thickness were taken from the upper border of third lumbar vertebra to the middle of shaft of the femur and the images were transferred to HDR Plus 3.0 treatment planning system (TPS). The organ at risks (OARs), including bladder, rectum, sigmoid, and high-risk clinical target volume $\left(\mathrm{CTV}_{\mathrm{HR}}\right)$ were contoured. $\mathrm{CTV}_{\mathrm{HR}}$ was defined based on the findings of examination under anesthesia during the insertion of applicator and CT scan images. Viswanathan et al. contouring guidelines were followed for CT-based contouring [13].

\section{Planning and execution of the treatment}

Applicators were digitized in the multi-planar reconstruction view. Surface control points were created on OARs and $\mathrm{CTV}_{\mathrm{HR}}$. Treatment plan was generated by inverse planning technique in HDR Plus 3.0 treatment planning system, using a task group (TG-43) algorithm. The dose constraints of $6.5 \mathrm{~Gy}$ to $\mathrm{CTV}_{\mathrm{HR}}, 5 \mathrm{~Gy}$ to $2 \mathrm{~cm}^{3}$ of bladder, 4 Gy to $2 \mathrm{~cm}^{3}$ of rectum and sigmoid were given. The plan was optimized to achieve better $D_{90} C_{T V}$ (dose received by $90 \%$ of $\mathrm{CTV}_{\mathrm{HR}}$ ) and minimize the dose to OARs by using isodose re-shaper tool. Four fractions of 6.5 Gy was delivered by Bebig Multisource HDR machine (Eckert \& Ziegler), with ${ }^{60} \mathrm{Co}$ source. Bladder was filled with $50 \mathrm{ml}$ of normal saline during all the fractions. Patient was hospitalized till the completion of all the four fractions of brachytherapy. Two fractions were delivered on the first day, with a gap of six hours and the remaining two fractions were delivered on the second day. All the four fractions were delivered by the same treatment plan. The tandem and needle positions were verified before every fraction.

\section{Follow-up}

All patients were followed-up 15 days after the completion of brachytherapy, then once in 3 months for 2 years and once in 6 months after 2 years. Clinical examination was performed for all the patients during the follow-up. Patients with suspected recurrence underwent intravenous contrast CT scan and biopsy. Sigmoidoscopy was performed for patients who suffered a bleeding per rectum.

\section{Dosimetric parameters}

The equieffective dose in 2 Gy $\left(\mathrm{EQD}_{2}\right)$ of $2 \mathrm{~cm}^{3}$ of bladder, rectum, sigmoid, $\mathrm{D}_{90} \mathrm{CTV}_{\mathrm{HR}}$, and dose homogeneity index (DHI), dose non-uniformity ratio (DNR), coverage index (CI), conformal index (COIN), and overdose volume index (OI) were calculated by using following formulas $[14,15,16]$ :

1. Equivalent dose in 2 Gy $\left(\mathrm{EQD}_{2}\right)=[\mathrm{nd}(1+\mathrm{d} / \alpha / \beta)] /$ $[1+(2 / \alpha / \beta)]$, where $\mathrm{n}$ is the number of fractions, $\mathrm{d}$ is the dose per fraction, $\alpha / \beta$ ratio with 3 for normal tissue and 10 for tumor.

2. Dose homogeneity index: $\mathrm{DHI}=\left(\mathrm{V}_{100}-\mathrm{V}_{150}\right) / \mathrm{V}_{100}$, where $\mathrm{V}_{100}$ and $\mathrm{V}_{150}$ are the volume of the $\mathrm{CTV}_{\mathrm{HR}}$ re- 
ceiving $100 \%$ and $150 \%$ of the prescribed dose, respectively.

3. Dose non-uniformity ratio: $\mathrm{DNR}=\mathrm{V}_{150} / \mathrm{V}_{100}$.

4. Conformal index: $\mathrm{COIN}=\mathrm{C}_{1} \times \mathrm{C}_{2}$, where $\mathrm{C}_{1}=\mathrm{V}_{100}$ and $\mathrm{C}_{2}$ is the volume receiving $100 \%$ of the prescribed dose, which is outside the $\mathrm{CTV}_{\mathrm{HR}}$.

5. Coverage index: $\mathrm{CI}=\mathrm{V}_{100} / \mathrm{CTV}_{\mathrm{HR}}$, where $\mathrm{CI}$ is the ratio of the volume of $\mathrm{CTV}_{\mathrm{HR}}$ receiving $100 \%$ of the prescribed dose to the total volume of $\mathrm{CTV}_{\mathrm{HR}}$.

6. Overdose volume index: $\mathrm{OI}=\mathrm{V}_{200} / \mathrm{V}_{100}$, where $\mathrm{OI}$ is the ratio of volume of $\mathrm{CTV}_{\mathrm{HR}}$ receiving $200 \%$ of the prescribed dose to the volume of $\mathrm{CTV}_{\mathrm{HR}}$ receiving $100 \%$ of the prescribed dose.

Descriptive statistics for dosimetric parameters were expressed as mean \pm standard deviation and median with range for continuous characteristics using Microsoft Excel.

The disease-free survival was calculated in months from the day of completion of brachytherapy till the day of diagnosis of the recurrence in patients who had a recurrence or the last follow-up for patients who did not had a recurrence. The local control rate at 2 years was reported in percentage as follows:

Local control rate $=\left(\mathrm{N}_{1} / \mathrm{N}_{2}\right) \times 100$, where $\mathrm{N}_{1}$ is the number of patients who did not had any local disease at 2 years, $N_{2}$ is the total number of patients included in the study.

Table 2. Patients' characteristics

\begin{tabular}{|c|c|}
\hline \multicolumn{2}{|l|}{ Parameter } \\
\hline Total no. of patients & 70 \\
\hline \multicolumn{2}{|l|}{ Age (years) } \\
\hline Median & 50 \\
\hline Range & $35-70$ \\
\hline \multicolumn{2}{|l|}{ Histopathology } \\
\hline Squamous cell carcinoma & $64(91.43 \%)$ \\
\hline Adeno cell carcinoma & $6(8.57 \%)$ \\
\hline \multicolumn{2}{|l|}{ FIGO stage } \\
\hline $\mathrm{IIB}$ & $9(12.86 \%)$ \\
\hline IIIA & $8(11.42 \%)$ \\
\hline $\mathrm{IIIB}$ & $48(68.57 \%)$ \\
\hline IVA & $5(7.14 \%)$ \\
\hline \multicolumn{2}{|l|}{ Follow-up (months) } \\
\hline Median & 19 \\
\hline Range & $10-38$ \\
\hline \multicolumn{2}{|l|}{ Clinical outcome at 2 year } \\
\hline No evidence disease & $61(87.14 \%)$ \\
\hline Local recurrence & $8(11.43 \%)$ \\
\hline Distant recurrence & $1(1.43 \%)$ \\
\hline
\end{tabular}

\section{Results}

Seventy patients who underwent interstitial implants were included in the study. Patient characteristics and dosimetric parameters are presented in Tables 2 and 3. The median age was 50 years (35-70 years). Squamous cell carcinoma was the most common cancer (91.43\%). About $90 \%$ of patients presented stage III disease. The median volume of bladder, rectum, sigmoid, and $\mathrm{CTV}_{\mathrm{HR}}$ were $107 \mathrm{~cm}^{3}\left(48-526 \mathrm{~cm}^{3}\right), 38 \mathrm{~cm}^{3}\left(10-112 \mathrm{~cm}^{3}\right)$, $21 \mathrm{~cm}^{3}\left(4-80 \mathrm{~cm}^{3}\right)$, and $63 \mathrm{~cm}^{3}\left(26-95.6 \mathrm{~cm}^{3}\right)$, respectively. The median $\mathrm{EQD}_{2}$ of $2 \mathrm{~cm}^{3}$ of bladder, rectum, sigmoid, and $\mathrm{D}_{90} \mathrm{CTV}_{\mathrm{HR}}$ were $70 \mathrm{~Gy}$ (53-75 Gy), $64 \mathrm{~Gy}$ (51-71 Gy), 48 Gy (44-72 Gy), and 77 Gy (70-86 Gy), respectively. The median DHI, DNR, CI, OI, and COIN were 0.58 (0.39$0.78), 0.42$ (0.22-0.61), 0.87 (0.59-0.97), 0.19 (0.09-0.30), and $0.74(0.52-0.85)$, respectively. The median $\mathrm{V}_{150}$ and $\mathrm{V}_{200}$ of $\mathrm{CTV}_{\mathrm{HR}}$ were $21 \mathrm{~cm}^{3}\left(6-44 \mathrm{~cm}^{3}\right)$ and $9.5 \mathrm{~cm}^{3}\left(2-23 \mathrm{~cm}^{3}\right)$, respectively. The median overall treatment time was 56 days (46-75 days). The median follow-up was 19 months (10-38 months). Sixty-one patients had no evidence of the disease at the end of two years. Eight patients had a local recurrence and one patient had a lung metastasis. All these nine patients were stage III disease at diagnosis and underwent palliative chemotherapy. The median disease-free survival was 18.5 months. The local control rate

Table 3. Dosimetric parameters

\begin{tabular}{|c|c|c|}
\hline Parameter & Median (range) & Mean \pm SD \\
\hline \multicolumn{3}{|l|}{ Volume $\left(\mathrm{cm}^{3}\right)$} \\
\hline Bladder & $107(48-526)$ & $126 \pm 80$ \\
\hline Rectum & $38(10-112)$ & $43 \pm 19$ \\
\hline Sigmoid & $21(4-80)$ & $25 \pm 14$ \\
\hline $\mathrm{CTV}_{\mathrm{HR}}$ & $63(26-95.6)$ & $62 \pm 17$ \\
\hline \multicolumn{3}{|l|}{$\mathrm{EQD}_{2}$} \\
\hline Bladder $\left(D_{2 \mathrm{~cm}}{ }^{3}\right)$ & $70(53-75)$ & $69 \pm 5.46$ \\
\hline $\operatorname{Rectum}\left(D_{2 \mathrm{~cm}}{ }^{3}\right)$ & $64(51-71)$ & $63 \pm 4$ \\
\hline Sigmoid $\left(D_{2 \mathrm{~cm}}{ }^{3}\right)$ & $48(44-72)$ & $51 \pm 6$ \\
\hline $\mathrm{CTV}_{\mathrm{HR}}\left(\mathrm{D}_{90}\right)$ & $77(70-86)$ & $77 \pm 4$ \\
\hline $\mathrm{DHI}$ & $0.58(0.39-0.78)$ & $0.58(0.08)$ \\
\hline COIN & $0.74(0.52-0.85)$ & $0.72(0.07)$ \\
\hline $\mathrm{Cl}$ & $0.87(0.59-0.97)$ & $0.85(0.08)$ \\
\hline DNR & $0.42(0.22-0.61)$ & $0.42(0.08)$ \\
\hline Ol & $0.19(0.09-0.30)$ & $0.19(0.05)$ \\
\hline $\mathrm{V}_{150} \mathrm{CTV} \mathrm{V}_{\mathrm{HR}}\left(\mathrm{cm}^{3}\right)$ & $21(6-44)$ & $22.43(8.48)$ \\
\hline$V_{200} \operatorname{CTV}_{H R}\left(\mathrm{~cm}^{3}\right)$ & $9.5(2-23)$ & $10(4.4)$ \\
\hline
\end{tabular}

$E B R T$ - external beam radiotherapy, $B T$ - brachytherapy, $E Q D_{2}$ - equivalent dose in $2 \mathrm{~Gy}, D_{2}$ - dose received by $2 \mathrm{~cm}^{3}$ volume, $D_{90}$-dose received by $90 \%$ of the volume, CTV $V_{H R}$ - high-risk clinical target volume, DHI-dose homogeneity index, COIN - conformity index, $\mathrm{Cl}$ - coverage index, DNR - dose non-uniformity ratio, $\mathrm{Ol}$-overdose volume index, $V_{150}$-volume received by $150 \%$ prescribed dose, $V_{200}$-volume received by $200 \%$ of prescribed dose 
at 2 years was $87.14 \%$. Two patients had grade 2 proctitis (2.8\%) and one patient developed grade 3 proctitis (1.4\%). The patient with grade 3 proctitis underwent argon photocoagulation. Recto-vaginal fistula was noticed in two patients with a local recurrence. One patient had vaginal stenosis. There was no grade 2 or higher bladder toxicities seen in the study.

\section{Discussion}

Interstitial brachytherapy is used in locally advanced cervical cancer to deliver higher dose to the target volume without increasing the dose to bladder and rectum. In earlier days, Paris technique was used in interstitial brachytherapy, which was based on point dosimetry [17] In the year 1997, the International Commission on Radiation Units and Measurements published the dose and volume specification for reporting interstitial brachytherapy (ICRU-58) [18]. The change from two-dimensional X-ray-based planning to three-dimensional CT/magnetic resonance imaging (MRI) image-based planning along with computerized dosimetry has improved the accuracy of treatment planning in brachytherapy $[9,19]$. According to the American Brachytherapy Society (ABS) recommendation, the $\mathrm{EQD}_{2}$ of $2 \mathrm{~cm}^{3}$ of bladder, rectum and sigmoid are < 90 Gy and < 75 Gy, respectively, for HDR interstitial brachytherapy, following 45 Gy of EBRT [7]. In the present study, the median $\mathrm{EQD}_{2}$ of $2 \mathrm{~cm}^{3}$ of bladder, rectum, and sigmoid was 70 Gy (53-75 Gy), 64 Gy (51-71 Gy), and 48 Gy (44-72 Gy), respectively. The $\mathrm{EQD}_{2}$ reported in different literatures using ${ }^{192} \mathrm{Ir}$ source for interstitial brachytherapy are presented in Table 4 . Kannan et al. in their study reported the median $\mathrm{EQD}_{2}$ to $2 \mathrm{~cm}^{3}$ of bladder, rectum, and sigmoid for acceptable late complications as $70.8,65.8$, and $57.3 \mathrm{~Gy}$, respectively [5]. In a study by Lee et al., the recommended dose to $2 \mathrm{~cm}^{3}$ of rectum should be less than 62 Gy to avoid the late rectal complication [20]. In the present study, we have observed that the dose to $2 \mathrm{~cm}^{3}$ of bladder, rectum, and sigmoid were within the recommended limits, as reported in the studies where ${ }^{192}$ Ir source was used for interstitial brachytherapy. A five years follow-up study by Tantivatana et al. in patients undergoing ICBT using ${ }^{192}$ Ir or ${ }^{60}$ Co sources did not find any significant difference in overall survival ( $77 \%$ vs. $81.9 \%)$, disease-free survival (73.1\% vs. $74.7 \%)$, and grade 3 and grade 4 complications ( $4.7 \%$ vs. $3.4 \%)$ [21]. The available literature using ${ }^{192} \mathrm{Ir}$ for ISBT have reported local control in the range of $61-88 \%$ at 2 to 3 years. In the present study, we have observed the local control of $87.14 \%$ at 2 years.

DHI, DNR, CI, OI, and COIN are the objective parameters used to evaluate the conformity of a brachytherapy plan. Ideally, the value of DHI, CI, and COIN should be one, and the value of DNR and OI should be zero. Sharma et al. used Paris technique for dose prescription and found that DHI, DNR, and COIN were $0.61,0.31$, and 0.79 , respectively [22]. Swetha et al. reported DHI, DNR, and COIN as 0.57, 0.43, and 0.73, respectively, in their study using inverse planning technique [23]. In the present study, the DHI, DNR, and COIN values were 0.57, 0.43 , and 0.72 , respectively, similar to Swetha et al.

The ICRU-89 recommends $\mathrm{D}_{90} \mathrm{CTV}_{\mathrm{HR}}$ to be $>85 \mathrm{~Gy}$ $\mathrm{EQD}_{2}$. The $\mathrm{EQD}_{2}$ of $\mathrm{D}_{90} \mathrm{CTV}_{\mathrm{HR}}$ in studies where CTbased planning was used were 70 to 82.9 Gy $[3,5,20,24]$. Lee et al. and Villalba et al. observed in their study that the $\mathrm{CT}$ images overestimated the $\mathrm{CTV}_{\mathrm{HR}}$ and OARs volumes, compared to MRI images [20,25]. Few authors have reported $\mathrm{EQD}_{2}$ of $\mathrm{D}_{90} \mathrm{CTV}_{\mathrm{HR}}$ in the range of 78.6 to $84.8 \mathrm{~Gy}$, using MRI-based planning $[25,26,27]$. In the present study, we observed $77 \mathrm{~Gy}$ of median $\mathrm{EQD}_{2}$ of $\mathrm{D}_{90} \mathrm{CTV}_{\mathrm{HR}}$, with the range of 73 to 81 Gy by CT-based planning. Ret-

Table 4. Comparison of $\mathrm{EQD}_{2}$ and local control

\begin{tabular}{|c|c|c|c|c|c|}
\hline Study (no. of patients) & $\begin{array}{l}\text { Total dose } \\
\text { EBRT + BT }\end{array}$ & $\begin{array}{c}\mathrm{D}_{90} \mathrm{CTV}_{\mathrm{HR}} \\
{[\mathrm{Gy}]} \\
\end{array}$ & $\begin{array}{c}\text { Bladder } D_{2 \mathrm{~cm}^{3}} \\
{[G \mathrm{y}]}\end{array}$ & $\begin{array}{c}\text { Rectum } \mathrm{D}_{2 \mathrm{~cm}^{3}} \\
{[\mathrm{~Gy}]}\end{array}$ & Local control \\
\hline $\begin{array}{l}\text { Murakami et al. [3] } \\
\text { (209) }\end{array}$ & $\begin{array}{c}50 \text { Gy }+6 \text { Gy x } \\
4 \text { fractions }\end{array}$ & 74.2 & 71.0 & 67.5 & $87.8 \%$ at 3 years \\
\hline $\begin{array}{l}\text { Kannan et al. [5] } \\
\text { (47) }\end{array}$ & $\begin{array}{c}45 \text { Gy }+3.75-5 \text { Gy } x \\
5 \text { fractions }\end{array}$ & $70-79$ & 70.83 & 65.79 & $61 \%$ at 2 years \\
\hline $\begin{array}{l}\text { Lee et al. [20] } \\
\text { (68) }\end{array}$ & $\begin{array}{c}45 \text { Gy }+3.9 \text { Gy x } \\
7 \text { fractions }\end{array}$ & 73.6 & 67.1 & 64.6 & $86 \%$ at 2 years \\
\hline $\begin{array}{l}\text { Souza et al. [24] } \\
(47)\end{array}$ & $\begin{array}{c}45 \text { Gy }+4.6 \times \\
4 \text { fractions or } \\
9.2 \text { Gy } \times 2\end{array}$ & 70.2 & 61.6 & 63.2 & $68 \%$ at 3 years \\
\hline Villalba et al. [25] & \multirow{3}{*}{$\begin{array}{c}50 \text { Gy }+4 \text { Gy } x \\
6 \text { fractions }\end{array}$} & & & & \multirow[t]{3}{*}{$88 \%$ at 3 years } \\
\hline CT (34) & & 75.8 & 79.8 & 75.3 & \\
\hline MRI (25) & & 78.6 & 77.1 & 69.90 & \\
\hline Bailleux et al. [27] & \multirow{3}{*}{$\begin{array}{c}46 \text { Gy }+ \\
7 \text { Gy } \times 3 \text { fractions }\end{array}$} & & & & \multirow[t]{3}{*}{$86.8 \%$ at 2 years } \\
\hline CT (16) & & 82.9 & 76.8 & 66.4 & \\
\hline MRI (17) & & 84.8 & 74.5 & 64.3 & \\
\hline $\begin{array}{l}\text { Present study } \\
\text { (70) }\end{array}$ & $\begin{array}{c}45 \text { Gy }+6.5 \text { Gy } x \\
4 \text { fractions }\end{array}$ & 77 & 70 & 64 & $87.14 \%$ at 2 years \\
\hline
\end{tabular}

$E Q D_{2}$ - equivalent dose in $2 \mathrm{~Gy}, C T$ - computed tomography, MRI - magnetic resonance imaging, $C T V_{H R}$ - high-risk clinical target volume, $D_{2 \mathrm{~cm}^{3}}-$ dose received by $2 \mathrm{~cm}^{3}$ volume, $D_{90}$ - dose received by $90 \%$ of the volume 
rospective analysis was the main limitation of our study. Other limitations included CT-based treatment planning because of limited resources and short-term follow-ups of the patients. However, all these patients will be followed-up further, and clinical outcomes will be recorded.

\section{Conclusions}

The dosimetric parameters, local control, and toxicities of high-dose-rate interstitial brachytherapy in cervical cancer patients treated by ${ }^{60} \mathrm{Co}$ radioactive source are similar compared to the available literatures using ${ }^{192} \mathrm{Ir}$ source.

\section{Disclosure}

The authors report no conflict of interest.

\section{References}

1. Chemoradiotherapy for Cervical Cancer Meta-analysis Collaboration (CCCMAC). Reducing uncertainties about the effects of chemo radiotherapy for cervical cancer: individual patient data meta-analysis. Cochrane Database Syst Rev 2010; 1: CD008285.

2. Lanciano RM Won M, Coia LR et al. Pre-treatment and treatment factors associated with improved outcome in squamous cell carcinoma of the uterine cervix: a final report of the 1973 and 1978 patterns of care studies. Int J Radiat Oncol Biol Phys 1991; 20: 667-676.

3. Murakami N, Kobayashi K, Kato T et al. The role of interstitial brachytherapy in the management of primary radiation for uterine cervical cancer. J Contemp Brachytherapy 2016; 8: 391-398.

4. Bansal I, Panda D, Rathi AK et al. Rationale, indications, techniques and applications of interstitial brachytherapy for carcinoma cervix. Asian J Oncol 2016; 2: 69-78.

5. Kannan N, Beriwal S, Kim H et al. High-dose-rate interstitial computed tomography-based brachytherapy for the treatment of cervical cancer: Early results. Brachytherapy 2012; 11: 408-412.

6. Podgorsak EB. Radiation oncology physics: a handbook for teachers and students. International Atomic Energy Agency (IAEA) 2005; 457.

7. Viswanathan AN, Beriwal S, De Los Santos JF et al. American Brachytherapy Society consensus guidelines for locally advanced carcinoma of the cervix. Part II: High dose rate brachytherapy. Brachytherapy 2012; 11: 47-52.

8. Pinn-Bingham M, Puthawala AA, Syed AM. Outcomes of high-dose-rate interstitial brachytherapy in the treatment of locally advanced cervical cancer: long-terms results. Int $\mathrm{J} R$ diat Oncol Biol Phys 2013; 85: 714-720.

9. International Commission on Radiation Units and Measurements report. Prescribing, Recording, and Reporting Brachytherapy for Cancer of the Cervix (ICRU report 89) Bethesda, 2013.

10. Vega RB, Barbee D, Talcott $W$ et al. Cost in perspective: direct assessment of American market acceptability of Co-60 in gynecologic high-dose-rate brachytherapy and contrast with experience abroad. J Contemp Brachytherapy 2018; 10: 503-509.

11. Strohmaier S, Zwierzchowski G. Comparison of ${ }^{60} \mathrm{Co}$ and ${ }^{192}$ Ir sources in HDR brachytherapy. J Contemp Brachytherapy 2011; 3: 199-208.

12. Richter J, Baier K, Flentje M. Comparison of ${ }^{60} \mathrm{Co}$ and ${ }^{192} \mathrm{Ir}$ sources in high dose rate after loading brachytherapy. Strahlenther Onkol 2008; 184: 187-192.
13. Viswanathan AN, Dimopoulos JC, Kirisits C et al. Computed tomography versus magnetic resonance imaging-based contouring in cervical cancer brachytherapy: Results of a prospective trial and preliminary guidelines for standardized contours. Int J Radiat Oncol Biol Phys 2007; 68: 491-498.

14. Hall EJ, Giaccia AJ. Radiobiology for the radiologist. $6^{\text {th }}$ ed. Lippincott Williams \& Wilkins, Philadelphia 2006.

15. Saw CB, Sundharalingam N, Wu A. Concept of dose non uniformity in interstitial brachytherapy. Int J Radiat Oncol Biol Phys 1993; 26: 519-527.

16. Poddar J, Sharma AD, Suryanarayan U et al. Calculation of dose volume parameters and indices in plan evaluation of HDR interstitial brachytherapy by MUPIT in carcinoma cervix. Indian J Cancer 2018; 55: 238-241.

17. Pierquin B, Dutreix A, Paine $\mathrm{CH}$ et al. The Paris system in interstitial radiation therapy. Acta Radiol Oncol Radiat Phys Biol 1978; 17: 33-48.

18. International Commission on Radiation Units and measurements report: Dose and volume specification for reporting interstitial therapy (ICRU report 58) Bethesda, 1997.

19. Derks K, Steenhuijsen JL, Berg HA et al. Impact of brachytherapy technique (2D versus $3 \mathrm{D}$ ) on outcome following radiotherapy of cervical cancer. J Contemp Brachytherapy 2018; 10: $17-25$.

20. Lee L, Damato A, Viswanathan AN. Clinical outcomes of high-dose-rate interstitial gynecologic brachytherapy using real-time CT guidance. Brachytherapy 2013; 12: 303-310.

21. Tantivatana T, Rongsriyam K. Treatment outcomes of highdose-rate intracavitary brachytherapy for cervical cancer: a comparison of Ir-192 versus Co-60 sources. J Gynecol Oncol 2018; 29: e86.

22. Sharma PK, Sharma PK, Swamidas JV et al. Dose Optimisation in gynaecological 3D image based interstitial brachytherapy using Martinez universal perineal interstitial template (MUPIT) - an institutional experience. J Med Phys 2014; 39: 197-202.

23. Swetha B, Ravikumar M, Katke A et al. Dosimetric comparison of various optimization techniques for high dose rate brachytherapy of interstitial cervix implants. J Appl Clin Med Phys 2010; 11: 225-230.

24. D'Souza D, Wiebe E, Patil N et al. CT-based interstitial brachytherapy in advanced gynecologic malignancies: Outcomes from a single institution experience. Brachytherapy 2014; 13: 225-232.

25. Villalba SR, Sancho JR, Palacin AO et al. Development and clinical implementation of a new template for MRI based intracavitary/interstitial gynaecologic brachytherapy for locally advanced cervical cancer: from CT-based MUPIT to the MRI compatible template Benidorm: Ten years of experience. J Contemp Brachytherapy 2016; 8: 404-414.

26. Yoshida K, Yamazaki H, Takenaka T et al. Preliminary results of MRI-assisted high-dose-rate interstitial brachytherapy for uterine cervical cancer. Brachytherapy 2015; 14: 1-8.

27. Bailleux C, Falk AT, Chand-Fouche $M$ et al. Concomitant cervical and transperineal parametrial high-dose-rate brachytherapy boost for locally advanced cervical cancer. J Contemp Brachytherapy 2016; 8: 23-31. 